\title{
Dietary fat manipulation and not apolipoprotein $E$ (epsilon) genotype has a significant impact on cytokine production - insights from the SATgene study
}

\author{
A. Koutsos ${ }^{1}$, S. Lockyer ${ }^{1}$, A. L. Carvalho-Wells ${ }^{1,2}$, A. M. Minihane ${ }^{1,3}$, K. G. Jackson ${ }^{1}$ \\ and J. A. Lovegrove ${ }^{1}$ \\ ${ }^{1}$ Hugh Sinclair Unit of Human Nutrition \& ICMR, University of Reading, RG6 6AP, UK, ${ }^{2}$ now Division of Restorative \\ Dental Services, UCL Eastman Dental Institute, WCIX 8LD, UK and ${ }^{3}$ now Department of Nutrition, Norwich Medical \\ School, University of East Anglia (UEA), Norwich NR4 7TJ, UK
}

It is recognised that polymorphisms in the apolipoprotein $(A P O) E$ (epsilon) gene play an important role in cardiovascular disease (CVD) risk $^{(1)}$. In addition to modestly higher plasma cholesterol, a pro-inflammatory phenotype has been reported in carriers of the APOE4 allele $^{(2)}$. Our aim was to explore the impact of chronic dietary fat manipulation on cytokines production according to $A P O E$ genotype.

Fifty two healthy participants (mean age 50 (SD 9) y and BMI 26.4 (SD 4.3) kg/m²) were prospectively recruited according to $A P O E$ genotype ( $n=26 \mathrm{E} 3 / \mathrm{E} 3$ and $n=26 \mathrm{E} 3 / \mathrm{E} 4)$, and assigned to three iso-energetic diets; low fat (LF, 24\% energy (E) from fat, $8 \% \mathrm{E}$ saturated fat (SFA)), high fat-high saturated fat (HSF, 38\% E fat, 18\%E SFA), and HSF with 3 g/d docosahexaenoic (HSF-DHA) diets, each for an 8-wk period in a sequential design. Fasting blood samples were collected at baseline and at the end of each of the intervention diets. Concentrations of interleukin (IL)-1 $\beta$, IL-6, IL-8, IL-10 and tumour necrosis factor (TNF)- $\alpha$ were measured in cell free supernatants derived from whole blood culture assays stimulated for $24 \mathrm{~h}$ with either 0.05 or $1 \mu \mathrm{g} / \mathrm{ml}$ of bacterial lipopolysaccharide (LPS), using a cytokine multiplex antibody bead kit (Invitrogen) ${ }^{(3)}$. Cytokine production was corrected for the number of monocytes in the whole blood cultures.

\begin{tabular}{|c|c|c|c|c|c|c|c|c|c|}
\hline \multirow[b]{2}{*}{ Cytokine } & \multicolumn{2}{|c|}{ Baseline (pg per $10^{3}$ monocytes) } & \multicolumn{2}{|c|}{ LF diet (pg per $10^{3}$ monocytes) } & \multicolumn{2}{|c|}{ HSF diet (pg per $10^{3}$ monocytes) } & \multicolumn{2}{|c|}{ HSF-DHA diet (pg per $10^{3}$ monocytes) } & \multirow[b]{2}{*}{$P$} \\
\hline & Mean & SEM & Mean & SEM & Mean & SEM & Mean & SEM & \\
\hline IL-1 $\beta$ & $9.46^{\mathrm{a}}$ & 0.75 & $11.5^{\mathrm{a}}$ & 0.98 & $11.1^{\mathrm{a}}$ & 0.86 & $10.1^{\mathrm{a}}$ & 1.09 & NS \\
\hline IL-6 & $48.9^{\mathrm{a}}$ & 3.96 & $62.5^{\mathrm{a}}$ & 7.40 & $55.7^{\mathrm{a}}$ & 4.47 & $52.5^{\mathrm{a}}$ & 5.53 & NS \\
\hline IL-8 & $380^{\mathrm{a}}$ & 46.5 & $454^{\mathrm{a}}$ & 38.6 & $419^{\mathrm{a}}$ & 44 & $348^{\mathrm{a}}$ & 34.7 & NS \\
\hline IL-10 & $1.14^{\mathrm{b}}$ & 0.13 & $1.41^{\mathrm{a}}$ & 0.14 & $1.21^{\mathrm{ab}}$ & 0.10 & $1.09^{\mathrm{b}}$ & 0.09 & 0.036 \\
\hline TNF- $\alpha$ & $2.94^{\mathrm{b}}$ & 0.38 & $3.90^{\mathrm{ab}}$ & 0.47 & $4.60^{\mathrm{a}}$ & 0.51 & $4.99^{\mathrm{a}}$ & 0.69 & 0.012 \\
\hline
\end{tabular}

Effect of dietary fat manipulation on cytokine production (pg per $10^{3}$ monocytes) by $0.05 \mu \mathrm{g} / \mathrm{ml}$ LPS-stimulated whole blood cultures of fifty two healthy subjects. NS, not

significant. ${ }^{\mathrm{a}, \mathrm{b}}$ Mean values within a row with unlike superscript letters were significantly different $(P \leq 0.05)$.

No diet*genotype interactions were found, although a significant diet interaction was observed for TNF- $\alpha$ and IL-10 production after stimulation with $0.05 \mu \mathrm{g} / \mathrm{ml}$ LPS $(P=0.012$ and $P=0.036$ respectively) and $1 \mu \mathrm{g} / \mathrm{ml}$ LPS $(P=0.006, P=0.049)$. TNF- $\alpha$ concentrations were higher $(P \leq 0.05)$ after the HSF diet compared with the baseline, whereas IL-10 was higher $(P \leq 0.05)$ after the LF diet compared with the baseline and HSF-DHA diet. Our study data suggests a greater sensitivity of monocyte cytokine production to the quality and quantity of dietary fat, than APOE genotype in healthy participants.

1. Song YQ, Stampfer MJ \& Liu SM (2004) Ann Intern Med 141, 137-147.

2. Jofre-Monseny L, Minihane AM \& Rimbach G (2008) Mol Nutr Food Res 52, 131-145.

3. Chowdhury F, Williams A \& Johnson P (2009) J Immunol Methods 340, 55-64. 